\title{
Effect of an unani formulation on lipid profile in rat
}

Coronary artery disease (CAD) is one of the most important cause of death all over world. ${ }^{[1]}$ Hyperlipidemia is one of the risk factors for CAD. Data show that $25-30 \%$ risk of CAD is reduced by treating hyperlipidemia. In unani pharmacopoeia several formulations with large or small number of ingredients have been described for the treatment of cardiovascular disorders. Some of the formulations are being used in unani medicine with good results. There is possibility of errors of interpretation during clinical use of such drugs. Therefore, it was considered worth while to evaluate the role of a formulation containing Bombyx mori, Nepata hindostana and Terminalia arjuna in hyperlipidemia. The study was conducted in the Department of Ilmul Advia, A.K. Tibbiya College and the Department of Pharmacology, J. N. Medical College, A.M.U., Aligarh, India. Adult albino rats of either sex weighting 150- $200 \mathrm{~g}$ were taken. They were provided standard diet (Lipton India) and water ad libitum. Twelve hours dark and light cycles were maintained. They were divided into 4 groups containing 6 animals each. The temperature was maintained $26 \pm 2{ }^{\circ} \mathrm{C}$.

Isoproterenol hydrochloride purchased from Sigma USA.

N. hindostana (Badranj boya), B. mori (Abraisham) and bark of T. arjuna were procured from Dawakhana Tibiyya College, A.M.U., Aligarh and were identified by comparison for its macroscopic and microscopic characters with authentic specimens of $N$. hindostana, B. mori and bark of T. arjuna at the Botanical Survey of India, and the Forest Reaserch Institute,Dehradun, India.The bark of $T$. arjuna and whole plant of $N$. hindostana were dried in shade, powered in electric grinder to a coarse 20-40 mash size and extracted in soxhlet apparatus with distilled water for six hours separately. The aqueous extract of $B$. mori (raw silk cocoon) was obtained by reflex method. All three extract were separately concentrated at water bath and stored at room temperature for use.
Extracts of Terminalia arjuna, Nepata hindostana and Bombyx mori were combined in ratio of 1:2:1 respectively and freshly dissolved in distilled water on each day before administration.

The animals were divided into four groups. Group I was given distilled water and served as control. Group II were given isoproterenol $20 \mathrm{mg} / 100 \mathrm{~g}$ body weight subcutaneously twice at interval of $24 \mathrm{~h}$ to induce myocardial necrosis. ${ }^{[2]}$ Group III was administered unani formulation in the dose of 100 $\mathrm{mg} / 100 \mathrm{~g}$ of body weight, p. 0 . daily for 61 days (The test drugs are likely to produce optimum benefit after over 40 days of treatment). Group IV was administered unani formulation in the dose of $100 \mathrm{mg} / 100 \mathrm{~g}$ of body weight, p.o. daily for 60 days followed by isoproterenol subcutaneously twice at interval of $24 \mathrm{~h}$. The dose was calculated in the usual manner by multiplying the unani clinical dose by factor 7 for rat. ${ }^{[3]}$ Twelve hours after second dose of isoproterenol the animals were sacrificed by cervical decapitation method. The blood was collected in plane vials, serum was separated by centrifugation and stored at $4^{\circ} \mathrm{C}$ till analysed.

The serum was analysed for total cholesterol and free cholesterol, ${ }^{[4]}$ triglycerides ${ }^{[5]}$ phospholipids, ${ }^{[6]}$ free fatty acids, ${ }^{[7]}$ high density (HDL), ${ }^{[8 \mid}$ low density (LDL) ${ }^{[9]}$ and very low density lipoproteins (VLDL) ${ }^{[10]}$ by using "Diagnostic kit Syntropic: UVVIS Spetrophotometer 117.

The results were analysed by one-way analysis of variance (ANOVA) followed by Dunnett's test. $\mathrm{P}<0.05$ was considered statistically significant. The study showed significant increase in total cholesterol, free cholesterol, triglycerides, phospholipids, free fatty acids, low density (LDL) and very low density lipoproteins (VLDL) in isoproterenol treated group as compared with their respective control but the levels were statistically same in control and in unani formulation pre treated rats. Serum level of high density lipoprotein (HDL)

\section{Table 1}

The effect of unani formulation on serum lipoproteins $(\mathrm{mg} / \mathrm{dl})$ in rats

\begin{tabular}{|c|c|c|c|c|c|c|c|c|c|}
\hline Lipid & & $\begin{array}{c}\text { Total } \\
\text { cholesterol }\end{array}$ & $\begin{array}{c}\text { Free } \\
\text { cholesterol }\end{array}$ & S.triglycerides & Phospholipids & $\begin{array}{l}\text { Free fatty } \\
\text { acid }^{@}\end{array}$ & $L D L$ & $V L D L$ & $H D L$ \\
\hline Control & & $60.7 \pm 6.2$ & $86.3 \pm 7.5$ & $21.1 \pm 2.3$ & $53.8 \pm 8.4$ & $40.1 \pm 5.5$ & $38.3 \pm 1.4$ & $23.3 \pm 2.3$ & $17.6 \pm 2.4$ \\
\hline Isop treated & & $147.5 \pm 8.4^{* *}$ & $126.4 \pm 5.1^{* *}$ & $75.2 \pm 6.2^{* *}$ & $117.4 \pm 10.0^{* *}$ & $112.2 \pm 8.6^{* *}$ & $72.3 \pm 4.1^{* *}$ & $39.8 \pm 2.2^{*}$ & $11.1 \pm 1.2^{*}$ \\
\hline UF & & $86.5 \pm 5.2$ & $56.9 \pm 2.3$ & $20.3 \pm 2.7$ & $56.1 \pm 4.3$ & $36.2 \pm 2.7$ & $32.4 \pm 2.2$ & $20.3 \pm 2.2$ & $19.0 \pm 1.7$ \\
\hline UF + Isop & & $82.8 \pm 6.2$ & $67.6 \pm 3.6$ & $27.7 \pm 5.5$ & $63.5 \pm 4.9$ & $44.1 \pm 4.2$ & $38.4 \pm 2.7$ & $28.3 \pm 3.2$ & $17.8 \pm 1.1$ \\
\hline One-way & $\mathrm{F}$ & 1158 & 1628 & 1113 & 827.3 & 1338 & 335 & 121 & 32.1 \\
\hline \multirow[t]{2}{*}{ ANOVA } & $d f$ & 3,20 & 3,20 & 3,20 & 3,20 & 3,20 & 3,20 & 3,20 & 3,20 \\
\hline & $P$ & $<0.001$ & $<0.001$ & $<0.001$ & $<0.001$ & $<0.001$ & $<0.001$ & $<0.01$ & $<0.01$ \\
\hline
\end{tabular}

Values are mean $\pm \mathrm{SD} . \mathrm{n}=6$ in each group. ${ }^{*} \mathrm{P}<0.01,{ }^{* *} \mathrm{P}<0.001$ compared to control; Isop $=$ Isoproterenol; UF $=$ Unani formulation; ${ }^{\circledR} \mathrm{measured}$ in $\mu \mathrm{mole} /$ dL. 
was lowest in isoproterenol treated groups as compared with control and unani formulation pre-treated group. [Table 1] All animals of different groups were given similar diet and there was no significant change in the body weight.

Research in cardiovascular pharmacology in the past few years has been mainly focussed on hypolipidemic agents including herbal drugs. B. mori and $N$ hindostana were reported as cardiotonic and cardioprotective drugs. T. arjuna is used in cardiovascular disorders.

It is well known that hyperlipidemia is one of the major risk factors for atherosclerosis. An increase in the concentration of lipids results in liberation of lisosome and trigger cells degeneration. Major component of total cholesterol is low density lipoprotein (LDL) which is directly related to CAD. It is recognised as major atherogenic lipoprotein and primary target of lipid lowering therapy. The serum low density lipoprotein (LDL) in unani formulation pre-treated group was lower as compared with isoproterenol treated group. High density lipoprotein (HDL) has preventive role in $\mathrm{CAD}$, it has been shown to reduce the endothelial incorporation of lysophosphatidyl cholines (lyso-PC). The HDL level was significantly raised in unani formulation pretreated group as compared with isoproterenol treated group. Recently more emphasis is given that elevated level of LDL-C is important factor for $\mathrm{CAD}$ and lowering its level through diet and medication has been shown to reduce the progression of CAD. Free fatty acid level was significantly high in isoproterenol treated animals as compared to unani formulation pre-treated animals. It is reported that increased free fatty acid is associated with a rise in myocardial oxygen consumption.

Silk cocoons and bark of $T$ arjuna mainly contain amino acids such as tyrosine, histidine, tryptophan, cysteine etc., which have been reported to act as antioxidants. The presence of soluble fibres and sitostanols (beta-sitosterol) could also explain the hypocholesterolaemic effect of arjuna bark. $N$ hindostana and $T$. arjuna both drugs have phenolic compounds and flavonoids abundantly, so they are potent quenchers of free radicals and also react quite rapidly with $\mathrm{O}_{2}$. In our study all the three ingredients of unani formulation have antioxidants compounds, which may be having protective role in hyperlipidemia.

Tajuddin*, M. Nasiruddin, N. Ahmad* Department of Ilmul Advia*, A.K. Tibbiya College and Department of Pharmacology, J. N. Medical College Aligarh Muslim University, Aligarh - 202002 (U.P.) E-mail : naseer_bettiah@yahoo.co.in

\section{References}

1. Gambhir DS, Gambhir JK, Sudha R. Dyslipidaemia and coronary heart disease. Management of issues from Indian prospective. Indian Heart $J$ 2001;52:515-6.

2. Wexler BC, Kittinger GH. Myocardial necrosis in rats. Serum enzymes, adrenal steroids and histopathological alterations. Cric Res 1978;13:159-71.

3. Freireich EJ. Quantitative comparision of toxicity of anticancer agents, in mouse, rat, dog, monkey and man. Cancer Chemother reports 1996;50:219-44.

4. Wybenga DR, Pilleggi. Determination of free cholesterol in serum/ plasma. Clin Chem 1970;16:980.

5. Bucolo G, David H. Determination of triglycerides in serum/ plasma. Clin Chem 1973;19:476.

6. Gomorri's method Detemination of phospholipids cited from Praful B Godker, Clinical Biochemistry. Mumbai, India: Bhalani Publishing House; 1984.

7. Trout PL, Estes EH, Friedberg SJ. Titration of free fatty acids of plasma. A study of current method and modification. J Lipid Res 1960;1:199-202.

8. Flegg HM. Estimation of highdensity lipoproteins. Ann Clin Biochem 1972;10:79-82.

9. Wieland $H$, Seidel J. Estimation of lowdensity lipoproteins by colorimetric method. J Lipid Res 1983;24:904-8.

10. Fredrickson SDS. Plasma lipoproteins and apolipoprotein cited from Praful B Godker. Clinical Biochemistry. Mumbai, India: Bhalani Publishing House;1972.

\title{
IPS WEBSITE \\ IPS has launched a website \\ www.gsips.org
}

Features: Online registration, Constitution and Member list at one click.

\section{Contact point:}

\author{
Dr. Prakash V. Diwan \\ General Secretary, IPS \\ Head, Pharmacology Division \\ Indian Institute of Chemical Technology \\ Hyderabad -500007 \\ E.mail: diwan@iict.res.in, diwan_prakash@rediffmail.com
}

